\section{Roots on display at Science Centre}

How do you obtain and display the root system of a tree for educational purposes? For a year now, part of the root system of a 70-year old white pine has been seen by many people at the Ontario Science Centre, Toronto, and has evoked much interest.

What tree to use? A root system with good horizontal and vertical development was required; the effect of soil conditions on development should be evident; for hydraulic excavation it had to be close to a water supply, the soil easily removed with water, and a slope was needed for drainage; it had to be free of other root systems; and it had to be not too far from the Centre and accessible by truck for removal.

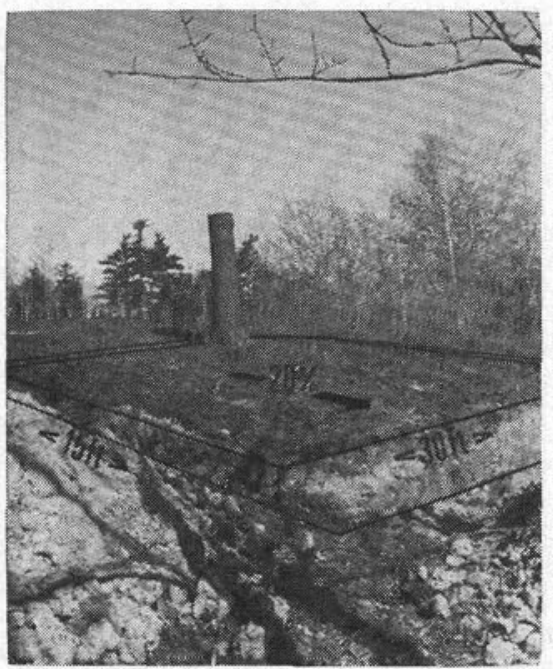

A field-grown white pine on the Ontario Ministry of Natural Resources' Research Station at Maple was finally selected. After the stem was felled, a 5-6 ft deep perimeter trench was dug with a backhoe around the downslope half of the root system; a drainage ditch was dug downslope. A few feet were left untrenched along the back side of the trunk to provide an area of support prior to removal of the system. The soil was from 2 to $5 \mathrm{ft}$ of sandy loam over a poorly structured clay. A few stones were present.

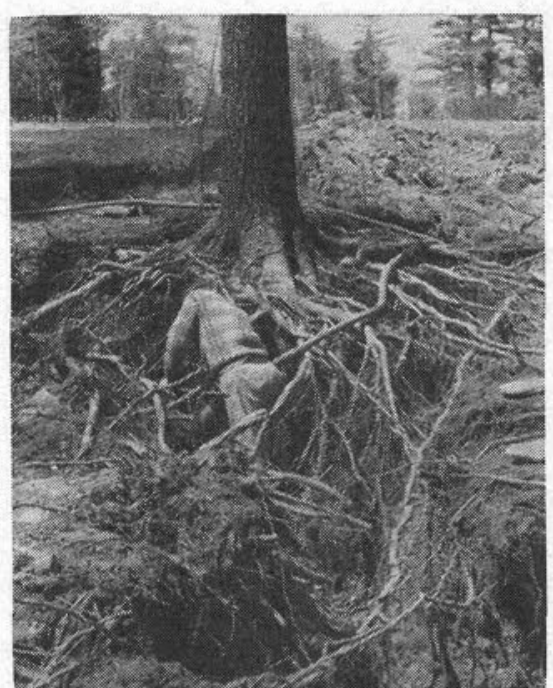

Finally the surface roots were laid out and held in place with fine wires. Application of a fire retardant, which imparted a wet look to the roots, and the addition of descriptive panels completed the display. The root system can be viewed from the mezzanine level or from the ground floor below.

The root system was selected, excavated and laid out by Dr D. C. F. Fayle of the Research Branch, Ontario Ministry of Natural Resources; the idea and design for the display came from Gordon Willson of the Science Centre; the staff of the Centre's Metal and Woodworking Shops under Dave Cunningham and Maurice Bendall got the root system into its resting place; and Ted Jenkins of Natural Resources recorded the event on film.

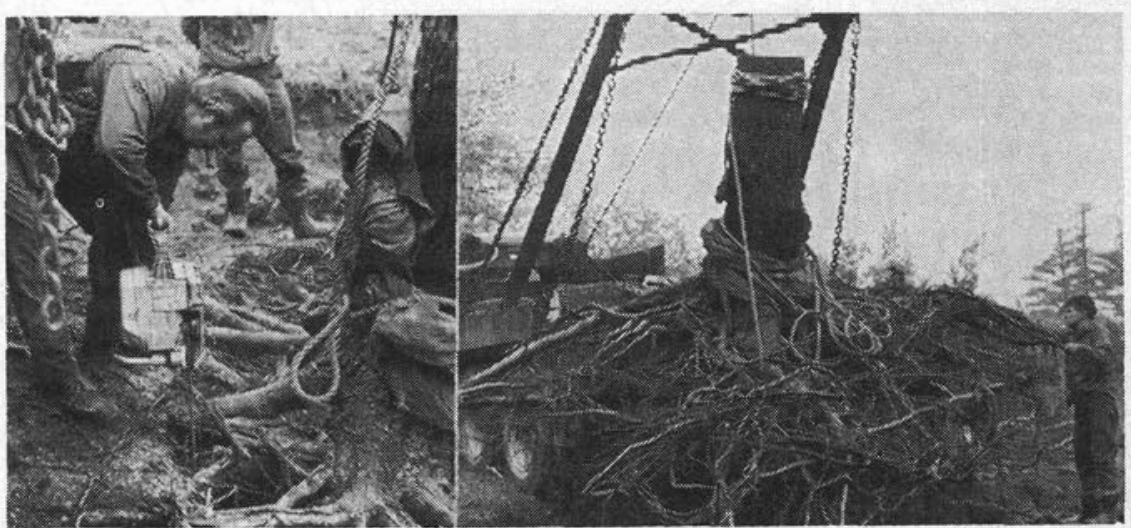

Hydraulic excavation took about 70 hours. When excavation was complete the supporting roots on the unexcavated side of the trunk were cut and the whole system lifted clear without any problems. Before lifting, some main surface roots were removed and fine roots coiled up to reduce the size of the system for transportation.

Once at the Centre the root system was transferred to a fork-lift truck and carefully manoeuvered through the large passageways of the Centre to its display area. The root system was then lifted some $18 \mathrm{ft}$ off the ground and the stem base securely fixed to the roof beams with rods, brackets and holts.

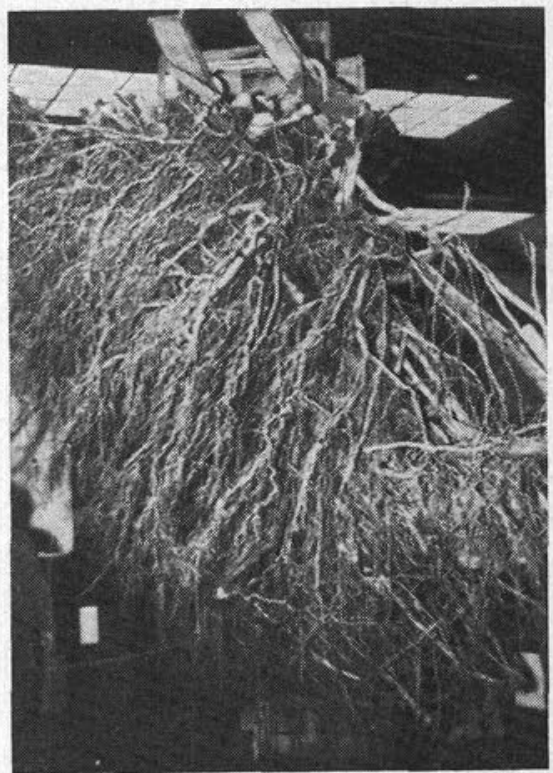

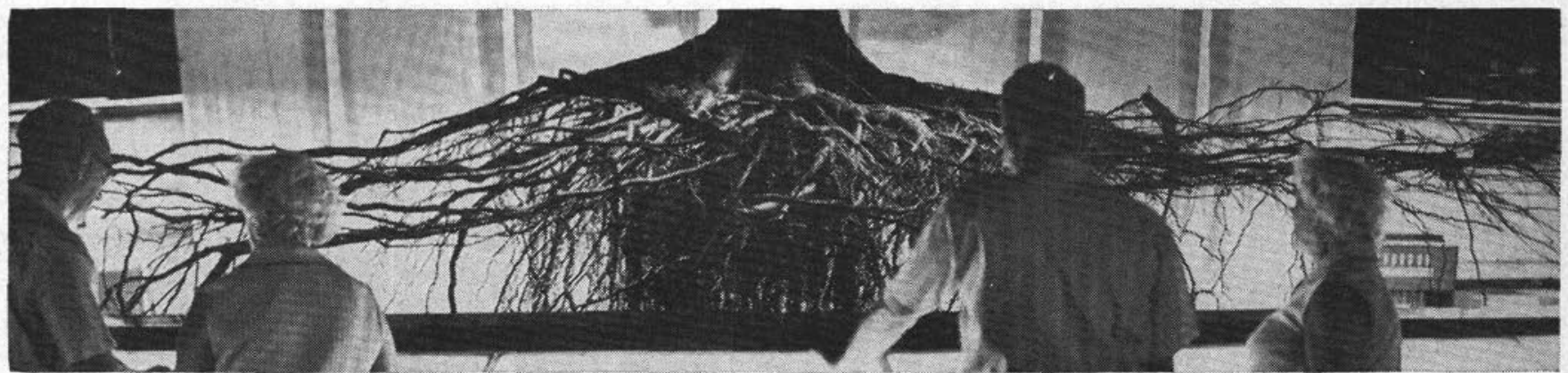

